\title{
Perioperative radiotherapy versus surgery alone for retroperitoneal sarcomas: a systematic review and meta-analysis
}

\author{
Alexandros Diamantis ${ }^{1}$, Ioannis Baloyiannis ${ }^{1}$, Dimitrios E. Magouliotis ${ }^{1}$, Maria Tolia ${ }^{2}$, \\ Dimitrios Symeonidis ${ }^{1}$, Effrosyni Bompou ${ }^{1}$, Georgios Polymeneas ${ }^{3}$, Konstantinos Tepetes ${ }^{1}$

\begin{abstract}
1 Department of General Surgery, University Hospital of Larisa, Mezourlo, Larisa, Thessaly, Greece
2 Department of Radiotherapy/Radiation Oncology, Faculty of Medicine, School of Health Sciences, University of Thessaly, University Hospital of Larissa, Biopolis, Greece

${ }^{3}$ Second Department of Surgery, National and Kapodistrian University of Athens, School of Medicine, Aretaieion University Hospital, Athens, Greece;
\end{abstract}

Radiol Oncol 2020; 54(1): 14-21.

Received 26 December 2020

Accepted 31 January 2020

Correspondence to: Diamantis Alexandros M.D., M.Sc., Ph.D., Department of General Surgery, University Hospital of Larissa, Mezourlo, Larissa, Thessaly, 41110, Greece. E-mail: alexandrosdoc@gmail.com

Disclosure: No potential conflicts of interest were disclosed.

Background. There is no clear evidence on whether radiotherapy (RT) improves treatment result in patients with retroperitoneal sarcomas (RPS).

Methods. A systematic literature search was performed using PubMed, Scopus and CENTRAL databases. Data were retrieved from published comparatives studies in patients with RPS undergoing surgery alone or RT plus surgery. The primary endpoints were the 5-year OS and the median OS. The secondary endpoints were the recurrence-free survival (RFS) and the RO-resection rate. Continuous outcomes were calculated by means of weighted mean difference (WMD).

Results. Ten out of 374 articles were analyzed. The median OS and the 5-year survival were significantly increased in patients treated with RT and surgery, compared to patients treated with surgery alone $(p<0.00001, p<0.001)$. Median RFS was significantly increased in patients treated with either preoperative $(p<0.001)$ or postoperative $(p=$ 0.001 ) RT compared to patients that underwent surgery alone. Finally, median R0-resection rate was similar between the two groups $(p=0.56)$.

Conclusion. RT along with radical surgery could be the standard of care in at least a subgroup of patients with RPS.

Key words: soft tissue sarcoma; adjuvant radiotherapy; neoadjuvant radiotherapy

\section{Introduction}

Retroperitoneal soft tissue sarcomas (RPS) constitute a rare and quite heterogeneous group of mesenchymal neoplasms that are located in the retroperitoneum and count for less than $10-15 \%$ of all soft tissue sarcomas (STSs). ${ }^{1}$ With an incidence of approximately $0,5-1$ case per 100000 , these tumors are most often considered sporadic especially in the absence of a genetic syndrome (Li-Fraumeni syndrome, Gardner's syndrome, familial adenomatous polyposis [FAP], Carney-Stratakis syndrome,
Hereditary retinoblastoma, etc.). ${ }^{2}$ Histological subtypes are the well-differentiated liposarcoma (WDLPS), leiomyosarcoma dedifferentiated liposarcoma (DDLPS), undifferentiated pleomorphic sarcoma, solitary fibrous tumors, malignant peripheral nerve sheath tumors and synovial sarcoma. ${ }^{3}$

Until now surgery with curative intent (R0 resection) remains the gold standard treatment for most patients with resectable disease contributing to long-term disease-free survival (DFS). ${ }^{4,5}$ However, complete macroscopic surgical resection 
is achieved in about $70 \%$ of the patients reflecting the high incidence of local recurrence and disease progression. ${ }^{6,7}$ Thus, multimodality treatment involving RT and/or chemotherapy could favor the ability to obtain negative surgical margins with a subsequently better local control of the disease and longer survival.

Radiotherapy to the retroperitoneum is a quite complex procedure and can be administered preoperatively, postoperatively, intraoperatively or even in a combined therapy setting. In the era of newer RT techniques as 3D-CRT and IMRT, the surrounding normal tissues can be protected and acute radiation induced adverse events can be reduced. ${ }^{5}$

While current literature is not clear on whether RT, either preoperatively or postoperatively, reflects on a beneficial result in patients with RPS, we aim to investigate if the combination of perioperative RT and surgical resection benefits the overall survival (OS) and the local control of the disease.

\section{Methods}

\section{Search strategy and articles selection}

The present meta-analysis was performed according to a protocol, which was agreed by all participating authors, along with the Preferred Reporting Items for Systematic Reviews and Meta-Analyses. ${ }^{8}$ A thorough literature search was performed in PubMed (Medline), Scopus (ELSEVIER), and the Cochrane Central Register of Controlled Studies (CENTRAL) databases (last search: October 25, 2018). The following terms were used in every possible combination: "radiotherapy", "radiation therapy", "surgery", "surgical resection", "retroperitoneal sarcoma". The inclusion criteria were: (i) articles with $\geq 10$ patients, (ii) English language, (iii) published from 1990 to 2018, and (iv) human subjects. Two independent investigators (AD, DEM) extracted the available data. Any discrepancies regarding the inclusion and/or exclusion of studies were discussed with the guarantor author (KT) until consensus was reached. Moreover, the kappa coefficient test was used in order to evaluate the level of agreement between the reviewers.

\section{Data extraction}

Regarding each study that was included, the extracted data was relative to baseline characteristics (sample size for each group, age, sex). The primary endpoints were the 5-year OS and the median OS.
The secondary end points were recurrence-free survival and R0 resection rate. Two authors (DEM, FB) performed the data extraction and compared the validity of the data until consensus was reached.

\section{Statistical analysis}

The categorical outcomes were evaluated by means of the Odds Ratio (ORs) and the 95\% confidence interval $(95 \% \mathrm{CI})$ were calculated by means of Fixed-Effects or Random-Effects model (MantelHaenszel statistical method). OR $<1$ denoted outcome that was greater in the RT group. Continuous outcomes were calculated by means of weighted mean difference (WMD) with its 95\% CI, using Fixed-Effects or Random-Effects (Inverse Variance statistical method) models, appropriately, in order to measure pooled estimates. In cases where WMD $<0$, the variables in the RT group were increased. The Cochran $Q$ statistic and the $I^{2}$ were calculated in order to assess the between-study heterogeneity. ${ }^{9}$ Forest plots were produced regarding the variables that were analyzed.

\section{Quality and publication bias evaluation}

The Newcastle-Ottawa Quality Assessment Scale $(\mathrm{NOS})^{10}$ was used in order to assess all non-Randomized Controlled Trials (non-RCTs) that were included. The scale ranges from zero to nine stars. The studies that were evaluated with a score equal to or higher than five were considered to have a good level of methodological quality and were finally included. No RCTs were identified and included in the current meta-analysis. Two authors (AD, DEM) rated the included studies independently and a final decision was reached by consensus.

The risk of publication bias was evaluated by the visual inspection of funnel plots. Publication bias could not be further evaluated by means of the Egger's formal statistical test ${ }^{11}$ due to the small number of the included studies (less than 10). As a result, the power of the test was significantly compromised.

\section{Results}

\section{Article selection and patient baseline characteristics}

The flow diagram of the present systematic review and meta-analysis is presented in Figure 1 (Prisma Flowchart) and the Prisma Checklist. In total, 374 ar- 
TABLE 1. Characteristics

\begin{tabular}{|c|c|c|c|c|c|c|c|c|c|c|c|}
\hline \multirow{2}{*}{ Study ID, Year } & \multirow{2}{*}{ Journal } & \multirow{2}{*}{ Country } & \multirow{2}{*}{$\begin{array}{l}\text { Time } \\
\text { Period }\end{array}$} & \multirow{2}{*}{$\begin{array}{l}\text { Type of } \\
\text { Study }\end{array}$} & \multicolumn{2}{|c|}{ Patients, $\mathrm{n}$} & \multicolumn{2}{|c|}{ Female, $\mathrm{n}(\%)$} & \multicolumn{2}{|c|}{ Median Age(Range) } & \multirow{2}{*}{$\begin{array}{l}\text { Stars In } \\
\text { Ottawa }\end{array}$} \\
\hline & & & & & SA & $\mathrm{RT}+\mathrm{S}$ & SA & $\mathrm{RT}+\mathrm{S}$ & SA & $\mathrm{RT}+\mathrm{S}$ & \\
\hline Kelly et al., $2015^{[12]}$ & Ann Surg & USA & 2003-2011 & $R$ & 172 & 321 & $84(49 \%)$ & 17 (53\%) & $62(26-92$ & $57(41-85)$ & 6 \\
\hline Nussbaum et al., 2016 [14] & Lancet Oncol & USA & $2003-2011$ & $R$ & 3322 & $\begin{array}{l}563^{1} \\
2196^{2}\end{array}$ & $1713(51,5 \%)$ & $\begin{array}{l}250(44 \%) \\
138(52 \%)\end{array}$ & $59,5( \pm 14,5)$ & $\begin{array}{c}59,2( \pm 13,8) \\
59,5( \pm 13,9)\end{array}$ & 6 \\
\hline Pierie et al., 2006 & EJSO & USA & 1973-1998 & $P$ & 21 & $41^{2}$ & N/A & N/A & N/A & N/A & 5 \\
\hline Stoeckle et al., $2001[7]$ & Cancer & France & 1980-1994 & $R$ & 55 & $89^{2}$ & N/A & N/A & N/A & N/A & 5 \\
\hline Stucky et al., 2014 [17] & J Surg Onc & USA & $1996-2011$ & $R$ & 26 & 371 & $9(35 \%)$ & $17(46 \%)$ & 74 & 56 & 6 \\
\hline Toulmonde et al., 2014 [18] & Annals of Oncology & France & 1988-2008 & $R$ & 262 & 127 & - & - & - & - & 5 \\
\hline Trovik et al., 2014 [19] & Acta Oncologica & Sweden & 1988-2009 & $R$ & 55 & 42 & $22(58,2 \%)$ & $15(33 \%)$ & $63(15-83)$ & $61(35-82)$ & 6 \\
\hline
\end{tabular}

SA = Surgery Alone; $\mathrm{RT}+\mathrm{S}=$ radiotherapy+Surgery); 1 = preoperative radiotherapy; 2 = postoperative radiotherapy

TABLE 2. SUmmary of the analysis of the categorical and continuous outcomes

\begin{tabular}{|c|c|c|c|c|c|}
\hline \multirow{2}{*}{ Categorical Outcomes } & \multirow{2}{*}{$\mathbf{n}$} & \multirow{2}{*}{ OR $(95 \% \mathrm{Cl})^{*}$} & \multirow{2}{*}{$p$} & \multicolumn{2}{|c|}{ Heterogeneity } \\
\hline & & & & $1^{2}$ & $p$ \\
\hline 5-year OS total & 9 & $0.69[0.62,0.77]$ & $<0.0001$ & $67 \%$ & 0.002 \\
\hline 5-year OS preoperative RT & 5 & $0.69[0.56,0.85]$ & 0.0005 & $50 \%$ & 0.09 \\
\hline 5-year OS postoperative RT & 4 & $0.69[0.61,0.79]$ & $<0.0001$ & $82 \%$ & 0.001 \\
\hline RFS total & 6 & $0.33[0.24,0.46]$ & $<0.0001$ & $69 \%$ & 0.006 \\
\hline RFS preoperative RT & 4 & $0.19[0.11,0.33]$ & $<0.0001$ & $72 \%$ & 0.001 \\
\hline RO resections total & 3 & $0.90[0.81,0.99]$ & 0.03 & $69 \%$ & 0.04 \\
\hline R0 resections preoperative RT & 2 & $1.21[0.65,2.25]$ & 0.56 & $82 \%$ & 0.02 \\
\hline $\mathrm{RO}$ resections postoperative $\mathrm{RT}$ & 1 & $0.89[0.81,0.98]$ & 0.02 & N/A & - \\
\hline Continuous outcomes & $\mathrm{n}$ & WMD $(95 \% \mathrm{Cl})$ & $p$ & $1^{2}$ & $p$ \\
\hline
\end{tabular}

$\mathrm{Cl}$ = Confidence Intervals; MOS = Median Overall Survival; OR = Odds Ratio; OS = Overall Survival; RFS = Recurrence Free Survival; RT = Radiotherapy; WMD=Weighted Mean Difference

ticles that were originally identified in PubMed, Scopus, and CENTRAL databases and ten articles were finally included in the quantitative synthesis. ${ }^{7,12-20}$ The level of agreement between the two reviewers was "very good" (kappa $=0.730 ; 95 \% \mathrm{CI}$ : $0.503,0.957)$. The study design was retrospective in nine studies ${ }^{7,12-14,16-20}$ and prospective in one study. ${ }^{15}$ The total baseline characteristics of the included studies are shown in Table 1. The NewcastleOttawa Scale (NOS) regarding all included studies and the quality assessment of the RCTs is presented in Table 1. Pooled ORs, $I^{2}$ along with $p$ values of heterogeneity regarding all outcomes that were measured are summarized in Table 2.

\section{Median overall survival (median-OS)}

The median OS was significantly higher in patients treated with preoperative RT followed by surgery compared to surgery alone (WMD: -22.93 [95\% CI: -27.91, -17.96]; $p<0.0001)$. The median-OS was also significantly higher in patients treated with surgical resection followed by postoperative RT compared to surgery alone group (WMD: -18.93 [95\% 
CI: -19.13, -18.74]; $p<0.0001)$. According to the total analysis, the median OS was significantly increased in patients treated with surgical resection and either neoadjuvant or adjuvant radiotherapy compared to surgery alone (WMD: -18.94 [95\% CI: -19.14, -18.74]; $p<0.00001$ ) (Figure 2).

\section{5-year survival}

The median 5-year survival was significantly increased in patients treated with preoperative RT followed by surgery compared to surgery alone (WMD: 0.69 [95\% CI: 0.56, 0.85]; $p=0.005$ ). The median 5-year survival was also significantly higher in patients treated with surgery followed by postoperative RT compared to surgery alone group (WMD: 0.69 [95\% CI: 0.61, 0.79]; $p<0.0001$ ). According to the total analysis, the 5-year survival was significantly increased in patients treated with surgery and either neoadjuvant or adjuvant therapy compared to surgery alone (WMD: 0.69 [95\% CI: 0.62, 0.77]; $p<0.0001$ ) (Figure 3).

\section{Median recurrence-free survival}

The median RFS was significantly increased in patients treated with surgical resection and either preoperative (WMD: 0.19 [95\% CI: 0.11, 0.33]; $p<$ 0.0001) or postoperative (WMD: 0.49 [95\% CI: 0.32, $0.75] ; \mathrm{p}=0.001) \mathrm{RT}$ compared to surgery alone (Figure 4).

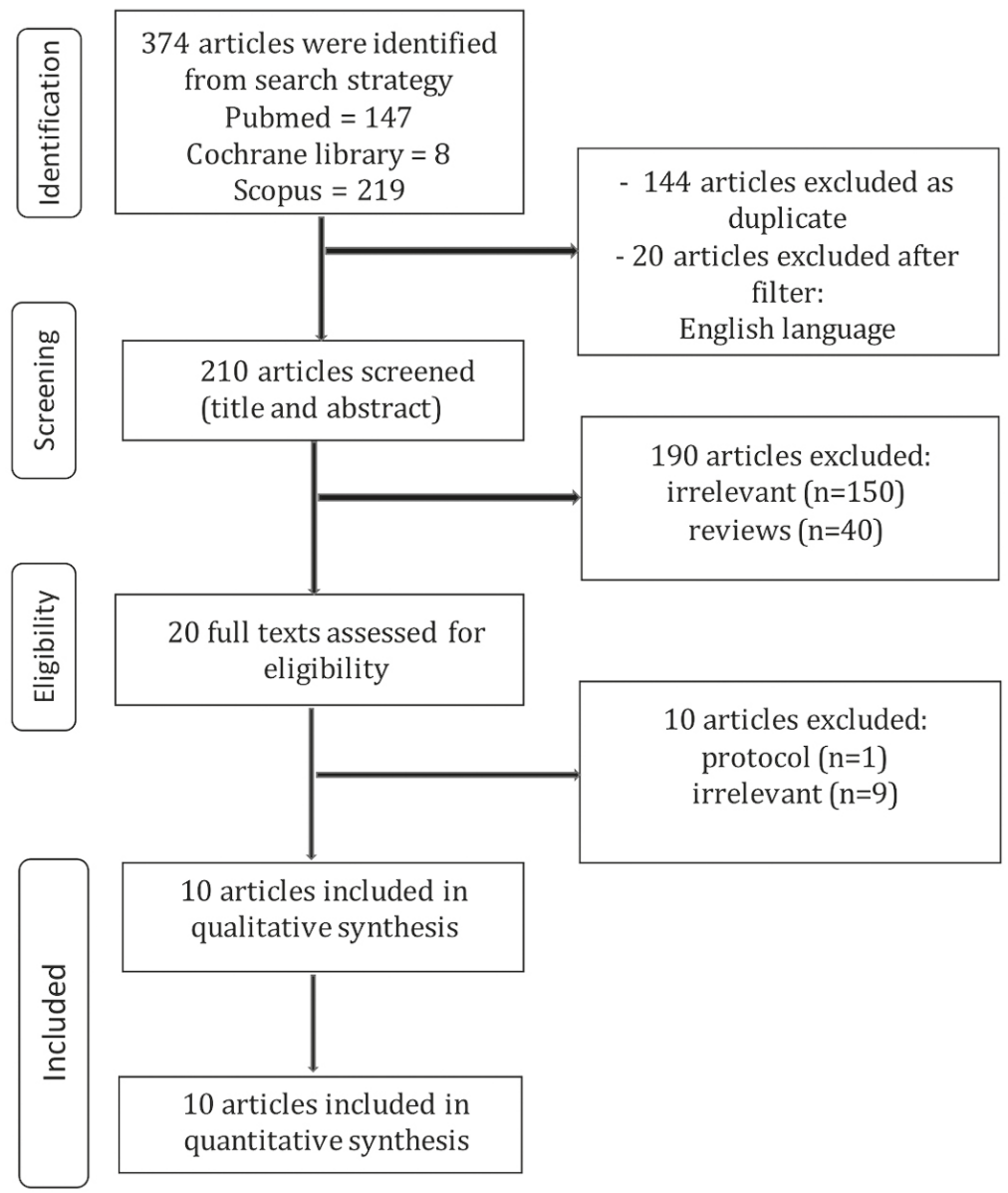

FIGURE 1. Prisma flowchart.

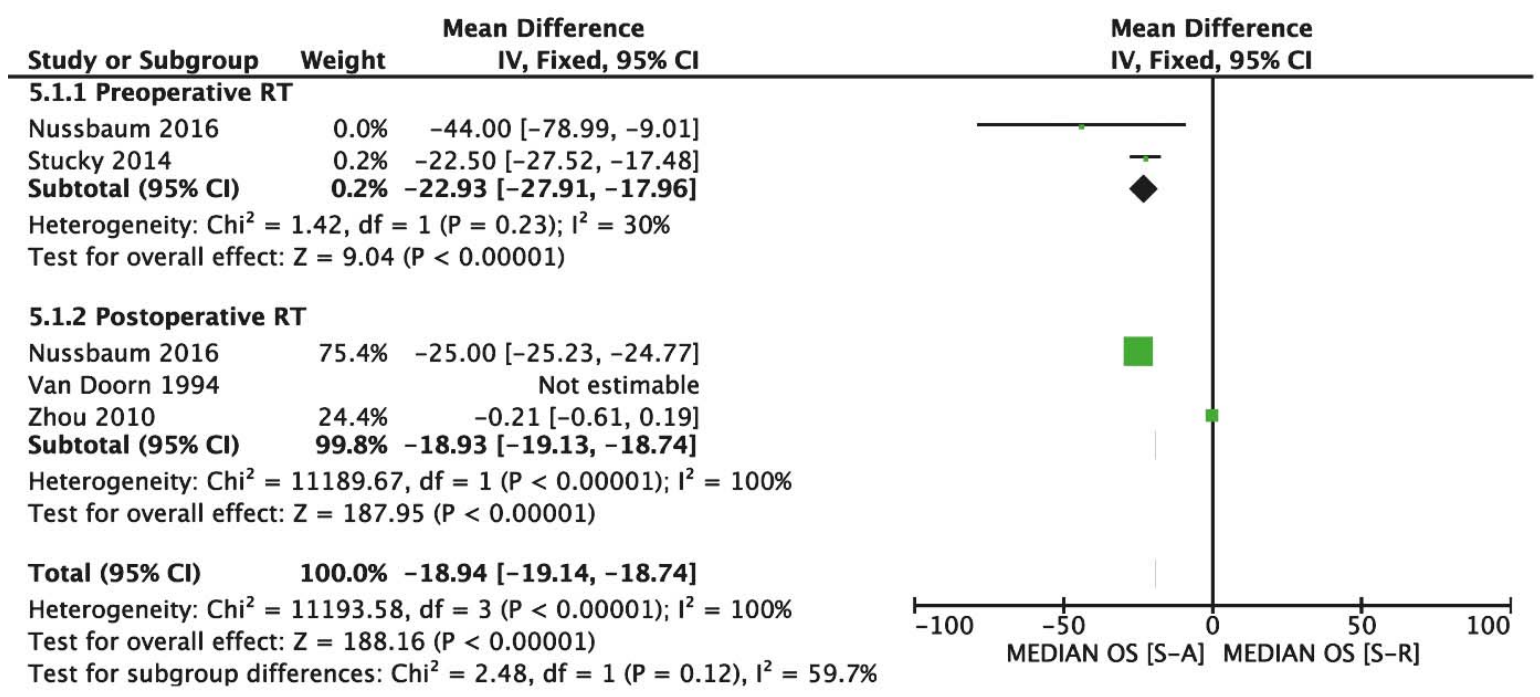

FIGURE 2. Median overall survival. 
Odds Ratio

Study or Subgroup Weight M-H, Fixed, 95\% Cl 1.1.2 S-A vs S-Preoperative $R$

Kelly 2015

Lane 2015

Nussbaum 2016

Smith 2014

Stucky 2014

Subtotal $(95 \% \mathrm{Cl})$

Total events

Heterogeneity: $\mathrm{Chi}^{2}=7.95, \mathrm{df}=4(\mathrm{P}=0.09) ; \mathrm{I}^{2}=50 \%$

Test for overall effect: $Z=3.51(P=0.0005)$

\subsubsection{S-A vs S-Postoperative $R$}

$\begin{array}{lrr}\text { Nussbaum 2016 } & 69.1 \% & 0.68[0.59,0.77] \\ \text { Pierie 2006 } & 1.4 \% & 0.25[0.07,0.86] \\ \text { Stoeckle 2001 } & 1.0 \% & 2.85[1.30,6.23] \\ \text { Trovik 2014 } & 2.1 \% & 0.45[0.19,1.05] \\ \text { Subtotal (95\% Cl) } & \mathbf{7 3 . 6 \%} & \mathbf{0 . 6 9}[0.61,0.79]\end{array}$

Total events

Heterogeneity: $\mathrm{Chi}^{2}=16.22, \mathrm{df}=3(\mathrm{P}=0.001) ; \mathrm{I}^{2}=82 \%$

Test for overall effect: $Z=5.62(P<0.00001)$

Total $(95 \% \mathrm{Cl})$

$100.0 \%$

$0.69[0.62,0.77]$

Total events

Heterogeneity: $\mathrm{Chi}^{2}=24.16, \mathrm{df}=8(\mathrm{P}=0.002) ; \mathrm{I}^{2}=67 \%$

Test for overall effect: $Z=6.62(P<0.00001)$

Test for subgroup differences: $\mathrm{Chi}^{2}=0.01, \mathrm{df}=1(\mathrm{P}=0.92), \mathrm{I}^{2}=0 \%$

FIGURE 3. 5-year overall survival.
Odds Ratio

M-H, Fixed, 95\% CI

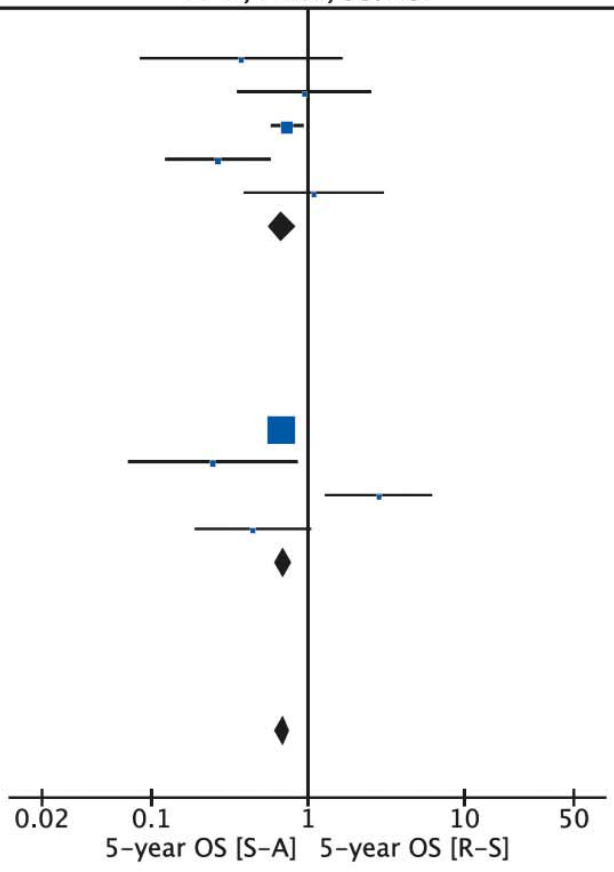

S-A

S-R

Odds Ratio

Odds Ratio

Study or Subgroup Events Total Events Total Weight $\mathrm{M}-\mathrm{H}$, Fixed, 95\% Cl 3.1.1 LRFS 5-y Preoperative

Kelly 2015

Lane 2015

Smith 2014

Stucky 2014

Subtotal $(95 \% \mathrm{Cl})$

Total events

$\begin{array}{rr}112 & 172 \\ 8 & 45 \\ 29 & 104 \\ 12 & 26 \\ & 347\end{array}$

161

$\begin{array}{rrrr}172 & 31 & 32 & 14.8 \% \\ 45 & 4 & 29 & 3.2 \%\end{array}$

$\begin{array}{llll}45 & 4 & 29 & 3.2 \%\end{array}$

$\begin{array}{llll}45 & 28 & 40 & 23.6 \%\end{array}$

$\begin{array}{llll}26 & 33 & 37 & 11.9 \%\end{array}$

347

$53.6 \%$

$1.35[0.37,4.97]$

$0.17[0.07,0.37]$

$0.10[0.03,0.38]$

$0.19[0.11,0.33]$

Heterogeneity: $\mathrm{Chi}^{2}=10.86, \mathrm{df}=3(\mathrm{P}=0.01) ; \mathrm{I}^{2}=72 \%$

Test for overall effect: $Z=5.93(P<0.00001)$

3.1.2 LRFS 5-y Postoperative

Stoeckle 2001

Toulmonde 2014

Subtotal $(95 \% \mathrm{CI})$

$8 \quad 23$

23
62

33

60

262
285

$42 \quad 127$

$36.8 \%$ 75

Heterogeneity: $\mathrm{Chi}^{2}=0.06, \mathrm{df}=1(\mathrm{P}=0.81) ; \mathrm{I}^{2}=0 \%$

Test for overall effect: $Z=3.27(P=0.001)$

Total $(95 \% \mathrm{Cl})$

$221 \quad 632 \quad 171$

Total events

$325100.0 \%$

$0.33[0.24,0.46]$

Heterogeneity: $\mathrm{Chi}^{2}=16.36, \mathrm{df}=5(\mathrm{P}=0.006) ; \mathrm{I}^{2}=69 \%$

Test for overall effect: $Z=6.59(P<0.00001)$

Test for subgroup differences: $\mathrm{Chi}^{2}=6.77, \mathrm{df}=1(\mathrm{P}=0.009), \mathrm{I}^{2}=85.2 \%$

$0.44[0.16,1.18]$

$0.50[0.31,0.81]$

$0.49[0.32,0.75]$

FIGURE 4. Median recurrence-free survival

\section{R0 resection rate}

The median R0 resection rate was similar between the groups of neoadjuvant therapy plus surgery compared to surgery alone (WMD: 1.21 [95\% CI: $0.65,2.25] ; \mathrm{p}=0.56$ ) (Figure 5).

\section{Publication bias}

Funnel plots seemed asymmetrical, with studies being absent from either top or bottom of the graph, thus posing certain publication bias. The small number of included studies was the main 
Odds Ratio

Odds Ratio

Study or Subgroup Weight $\mathrm{M}-\mathrm{H}$, Fixed, $95 \% \mathrm{Cl}$

M-H, Fixed, 95\% C

\begin{tabular}{|c|c|c|}
\hline \multicolumn{3}{|c|}{ 2.1.1 Preoperative radiotherapy } \\
\hline Kelly 2015 & $1.1 \%$ & $2.01[0.94,4.32]$ \\
\hline $\begin{array}{l}\text { Stucky } 2014 \\
\text { Subtotal }(95 \% \mathrm{Cl})\end{array}$ & $\begin{array}{l}1.0 \% \\
2.1 \%\end{array}$ & $\begin{array}{l}0.37[0.11,1.20] \\
1.21[0.65,2.25]\end{array}$ \\
\hline \multicolumn{3}{|c|}{$\begin{array}{l}\text { Total events } \\
\text { Heterogeneity: } \mathrm{Chi}^{2}=5.60, \mathrm{df}=1(\mathrm{P}=0.02) ; \mathrm{I}^{2}=82 \% \\
\text { Test for overall effect: } \mathrm{Z}=0.59(\mathrm{P}=0.56)\end{array}$} \\
\hline \multicolumn{3}{|c|}{ 2.1.2 Postoperative radiotherapy } \\
\hline $\begin{array}{l}\text { Nussbaum } 2016 \\
\text { Subtotal }(95 \% \mathrm{CI})\end{array}$ & $\begin{array}{l}97.9 \% \\
\mathbf{9 7 . 9 \%}\end{array}$ & $\begin{array}{l}0.89[0.81,0.98] \\
0.89[0.81,0.98]\end{array}$ \\
\hline \multicolumn{3}{|c|}{$\begin{array}{l}\text { Total events } \\
\text { Heterogeneity: Not applicable } \\
\text { Test for overall effect: } Z=2.29(P=0.02)\end{array}$} \\
\hline Total $(95 \% \mathrm{Cl})$ & $100.0 \%$ & $0.90[0.81,0.99]$ \\
\hline $\begin{array}{l}\text { Total events } \\
\text { Heterogeneity: } \mathrm{Chi}^{2} \\
\text { Test for overall effe }\end{array}$ & $\begin{array}{l}.53, \mathrm{df} \\
=2.17\end{array}$ & $\begin{array}{l}(P=0.04) ; I^{2}=69 \% \\
=0.03)\end{array}$ \\
\hline
\end{tabular}

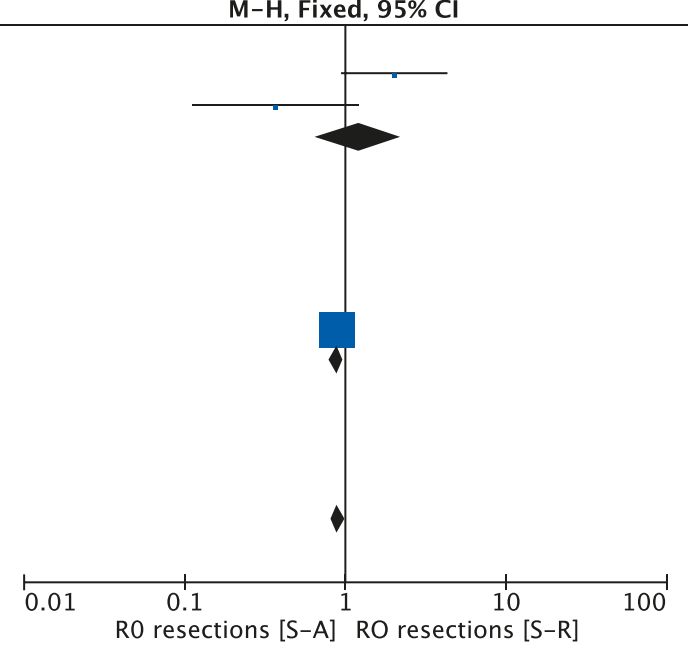

FIGURE 5. RO resection rate.

reason for the reported asymmetry. Egger test could not be performed because of the inadequate number of studies that were included. Finally, data retrieved is all but in one from retrospective studies and no randomized studies were included.

\section{Discussion}

Notwithstanding all the accumulated experience and knowledge regarding the diagnosis and treatment of patients with RPS through the past years, still, those patients' management remains challenging. Current literature evidence is quite insufficient on treatment strategies based mainly on retrospective single-center series, covering small patients' numbers, and treated with various combinations of surgical approaches, with or without adjuvant treatment modalities.

Surgical resection is adequate only when R0 excision of the RPS is feasible. However, due to its late presentation and its tendency to grow in close proximity with vital abdominal structures, in many cases, multivisceral excisions are needed to achieve a good oncologic outcome making it quite difficult to avoid either macroscopic or microscopic residual disease. RPS is often diagnosed in advanced stage, as it is often asymptomatic, and it makes complete excision difficult. Even after aggressive surgical treatment, the median survival of affected patients is 74 months and 5-year all survival rate is $36-58 \%$ with recurrence rates often $>50 \% \%^{1,2,4}$, dictating the need of better local control of the disease.
On this basis, RT could be a logical addition to the patient's management. Only a few studies have tested in a prospective manner the efficacy of RT in patients with RPS either on a neoadjuvant or adjuvant setting. Pierie et al., studied prospectively 103 consecutive patients who were treated for primary RPS and concluded that the most important factor influencing OS and recurrence rate was the complete resection of the disease, and only in patients at high risk of recurrence (i.e. high-grade tumors, positive microscopic margins) the addition of RT (IORT plus EBRT) can improve OS and local control of the disease with acceptable level of complications. $^{15}$

Stucky et al., after reviewing 63 consecutive RPS patients concluded that the combination of preoperative radiation plus surgical resection and intraoperative radiation results in excellent local disease control for RPS but not respectively improves overall survival. ${ }^{17}$ Moreover, postoperative RT improves the local control of the disease in combination with conservative surgery in patients with negative, marginal or minimally microscopically positive surgical margins. Stoeckle et al. stated that adjuvant RT represents the most important prognostic factor for local control of the disease since it is associated with significantly reduced local recurrence rates. ${ }^{7}$ High-grade tumors and margin positivity status are at higher risk for local failure and can be considered for intensification of therapy. ${ }^{15}$ The combination of surgery, Intraoperative RT (IORT) plus External Beam RT (EBRT) yields favorable local control and survival data. ${ }^{27}$ On the 
contrary, Pirayeshand et al., re-emphasized the poor outcome of patients with RPS and failed to find any connection between adjuvant RT or chemotherapy and a better outcome either on survival or local control of the disease. ${ }^{21}$

In our metanalysis, it was found that RT delivered either preoperatively or postoperatively, is associated with better median overall and median 5 -year survival. In concordance with the results of other retrospective studies, perioperative RT also favors recurrence-free survival compared to surgery alone. ${ }^{12,13,16}$ Interestingly, RT did not affect the $\mathrm{R} 0$ resection rates as previously reported in the literature..$^{12}$ Thus, patients with RPS should be assessed within a multidisciplinary sarcoma tumor board in order to consider RT in their treatment strategy.

Regardless of the timing chosen for RT, physicians should also try to limit the dose of radiation to the surrounding normal tissues. High attention is required in regards to the small bowel, especially in the setting of adjuvant treatment, that may fall into space previously occupied by the removed sarcoma mass and get exposed to high doses of irradiation resulting sometimes in serious complications even in perforation and peritonitis if incidental inclusion of the bowel occurs, especially during IORT. ${ }^{24}$ According to current experience, preoperative radiotherapy should be probably preferred. More specifically, the potential advantages of preoperative RT treatment are a) The decrease of residual microscopic local malignant cells. b) Radiosensitivity is higher due to better-oxygenated cells since postsurgical area represents a potentially more radio-resistant hypoxic region). A more radiosensitive target allows the delivery of lower doses of radiation, smaller field sizes and lower toxic adverse events from surrounding organs at risk. ${ }^{23-25}$ c) Postoperative adhesions can induce inhomogeneities in the radiotherapeutic treatment plan and suboptimal RT delivery. d) RT can lead to tumor down-sizing / staging. e) RT enables more limited surgery and reduces the amount of normal tissue that needs to be removed. f) RT decreases tumor seeding at the time of surgery. g) In some cases of marginally resectable locally advanced disease, RT can achieve resectability. h) RT may increase $\mathrm{R} 0$ resection rate as a result of pseudocapsule that forms around the tumor. ${ }^{26}$

In the modern era, the use of newer and more sophisticated RT techniques as 3D-CRT and IMRT and conformal treatment planning can facilitate surrounding normal organ sparing and avoid acute radiation-adverse events such as enteritis, anorexia, nausea/vomiting and late sequelae as peritonitis. ${ }^{28} \mathrm{CT}$ simulation and four-dimensional CT (4D-CT) scan for the assessment of the respiratory movement, allow the minimization of the RT dose to the normal tissues, and reduce the incidence of toxicity with excellent local control of the disease. ${ }^{28-30}$

Given the rarity of the disease, proper treatment of RPS must be investigated and determined only after multi-institutional participation in large randomized control trials. STRASS trial is the first, phase III, randomized, multicenter, EORTC study trying to assess whether there is a difference in abdominal recurrence-free survival between RPS patients treated with preoperative RT followed by surgery compared to surgery alone. ${ }^{22}$ The results of STRASS trial were presented at the ASCO meeting in 2019 and failed to demonstrate a benefit of preoperative RT for RPS showing no difference in RFS between neoadjuvant RT and surgery vs. surgery alone arms with the exception of liposarcomas in an unplanned subset analysis. There was also, no difference in OS between the two groups. However, in the propensity matched analysis, there was a trend towards improved RFS and LR in the RT arm.

\section{Limitations}

Several limitations should be considered before appraising the results of this study. The limitations of this meta-analysis reflect the limitations of the studies included. Nine studies $(90 \%)$ were retrospective $^{7,12,13,15-20}$ and one study $(10 \%)$ was prospective. ${ }^{14}$ No RCT was included. The studies used in this meta-analysis exhibit considerable heterogeneity, limiting the validity of the comparisons between studies and conclusions drawn. Finally, the small number of the included studies poses a publication bias, as it reflects the asymmetry of funnel plots.

\section{Conclusions}

After taking into consideration certain limitations, in our metanalysis perioperative RT is associated with improved OS and lower recurrence rates and should be offered selectively, to patients with RPS in the frame of a multidisciplinary team meeting. However, multicentered randomized trials are needed to confirm or revoke these results and assess which patients with RPS could have the greatest clinical and oncological benefit. If the results of these trials confirm the results of our meta-anal- 
ysis, which until now comprise the best evidence available, RT along with radical surgery could be the standard of care in at least a subgroup of patients with RPS. This subgroup taking into consideration the STRASS trial's results is probably the LPS subgroup, but this remains to be confirmed in future studies.

\section{References}

1. Brennan MF, Antonescu CR, Moraco N, Singer S. Lessons learned from the study of 10,000 Patients with soft tissue sarcoma. Annals of Surgery 2014 260: 416-22. doi: 10.1097/sla.0000000000000869

2. Trans-Atlantic RPS Working Group. Management of primary retroperitoneal sarcoma (RPS) in the adult: a consensus approach from the Trans-Atlantic RPS Working Group. Ann Surg Oncol 2014; 22: 256-63. doi: 10.1245/ S10434-014-3965-2

3. Coindre JM, Terrier $P$, Guillou $L$, Le Doussal V Collin $F$, Ranchère $D$, et al. Predictive value of grade for metastasis development in the main histologic types of adult soft tissue sarcomas: a study of 1240 patients from the French Federation of Cancer Centers Sarcoma Group. Cancer 2001; 91: 1914-26. doi: 10.1002/1097-0142(20010515)91;103.0.co;2-3

4. Anaya DA, Lev DC, Pollock RE. The role of surgical margin status in retroperitoneal sarcoma. J Surg Oncol 2008; 98: 607-10. doi: 10.1002/jso.21031

5. Bremjit PJ, Jones RL, Chai X, Kane G, Rodler ET, Loggers ET, et al. A contemporary large single- institution evaluation of resected retroperitoneal sarcoma. Ann Surg Oncol 2014; 21: 2150-8. doi: 10.1245/s10434-014-3616-7

6. Gronchi A, Casali PG, Fiore M, Mariani L, Lo Vullo S, Bertulli R, et al. Retroperitoneal soft tissue sarcomas: patterns of recurrence in 167 patients treated at a single institution. Cancer 2004; 100: 2448-55. doi: 10.1002/ cncr.20269

7. Stoeckle $\mathrm{E}$, Coindre JM, Bonvalot $\mathrm{S}$, Kantor $\mathrm{G}$, Terrier $\mathrm{P}$, Bonichon $\mathrm{F}$, et al. Prognostic factors in retroperitoneal sarcoma: a multivariate analysis of a series of 165 patients of the French Cancer Center Federation Sarcoma Group. Cancer 2001; 92: 359-68. doi: 10.1002/1097-0142(20010715)92:2<359::aidcncr1331>3.0.co;2-y

8. Liberati A, Altman DG, Tetzlaff J, Mulrow C, Gøtzsche PC, loannidis JP, et al. The PRISMA statement for reporting systematic reviews and meta-analyses of studies that evaluate health care interventions: explanation and elaboration. J Clin Epidemiol 2009; 62: e1-34. doi: 10.1016/j.jclinepi.2009.06.006

9. Higgins JPT, Green S. Cochrane handbook for systematic reviews of interventions Version 5.1.0 [updated March 2011]. The Cochrane Collaboration. 2011 [cited 2019 NOv 15]. Available at: www.cochrane-handbook.org

10. Stang A. Critical evaluation of the Newcastle-Ottawa scale for the assessment of the quality of nonrandomized studies in meta-analyses. Eur J Epidemiol 2010; 25: 603-5. doi: 10.1007/s10654-010-9491-z

11. Egger M, Davey Smith G, Schneider M, Minder C. Bias in meta-analysis detected by a simple, graphical test. BMJ 1997; 315: 629-34. doi: 10.1136/ bmj.315.7109.629

12. Kelly KJ, Yoon SS, KUK D, Qin LX, Dukleska K, Chang KK, et al. Comparison of perioperative radiation therapy and surgery versus surgery alone in 204 patients with primary retroperitoneal sarcoma: a retrospective two-institution study. Ann Surg 2015; 262: 156-62. doi: 10.1097/SLA.0000000000001063

13. Lane WO, Cramer CK, Nussbaum DP, Speicher PJ, Gulack BC, Czito BG, et al. Analysis of perioperative radiation therapy in the surgical treatment of primary and recurrent retroperitoneal sarcoma. J Surg Oncol 2015; 112: 352-8. doi: 10.1002/jso.23996.

14. Nussbaum DP, Rushing CN, Lane WO, Cardona DM, Kirsch DG, Peterson $\mathrm{BL}$, et al. Preoperative or postoperative RT versus surgery alone for retroperitoneal sarcoma: a case-control, propensity score-matched analysis of a nationwide clinical oncology database. Lancet Oncol 2016; 17: 966-75. doi: 10.1016/S1470-2045(16)30050-X

15. Pierie JP, Betensky RA, Choudry U, Willett CG, Souba WW, Ott MJ. Outcome in a series of 103 retroperitoneal sarcomas. Eur J Surg Oncol 2006; 32: 1235 41. doi: 10.1016/j.ejso.2006.07.002
16. Smith MJ, Ridgway PF, Catton CN, Cannell AJ, O'Sullivan B, Mikula LA, et al. Combined management of retroperitoneal sarcoma with dose intensification radiotherapy and resection: long-term results of a prospective trial. Radiother Oncol 2014; 110: 165-71. doi: 10.1016/j.radonc.2013.10.041

17. Stucky CC, Wasif N, Ashman JB, Pockaj BA, Gunderson LL, Gray RJ. Excellent local control with preoperative radiation therapy, surgical resection, and intraoperative electron radiation therapy for retroperitoneal sarcoma. J Surg Oncol 2014; 109: 798-803. doi: 10.1002/jso.23576

18. Toulmonde $M$, Bonvalot $S$, Méeus $P$, Stoeckle $E$, Riou $O$, Isambert $N$, et al. Retroperitoneal sarcomas: patterns of care at diagnosis, prognostic factors and focus on main histological subtypes: a multicenter analysis of the French Sarcoma Group. Ann Oncol 2014; 25: 735-42. doi: 10.1093/annonc/ mdt577

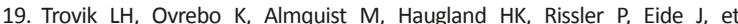
al. Adjuvant radiotherapy in retroperitoneal sarcomas. A Scandinavian Sarcoma Group study of 97 patients. Acta Oncol 2014; 53: 1165-72. doi: 10.3109/0284186X.2014.921723

20. Zhou Z, McDade TP, Simons JP, Ng SC, Lambert LA, Whalen GF, et al. Surgery and Radiotherapy for Retroperitoneal and Abdominal Sarcoma. Arch Surg 2010; 145: 426-31. doi: 10.1001/archsurg.2010.70

21. Pirayesh A, Chee Y, Helliwell TR, Hershman MJ, Leinster SJ, Fordham MV, et al. The management of retroperitoneal soft tissue sarcoma: A single institution experience with a review of the literature. Eur J Surg Oncol 2001; 27: 491-7. doi: 10.1053/ejso.2001.1146

22. Bonvalot S, Gronchi A, Le Pechoux C, Swallow CJ, Strauss DC, Meeus $P$, et al. STRASS (EORTC 62092): a phase III randomized study of preoperative radiotherapy plus surgery versus surgery alone for patients with retroperitoneal sarcoma. J Clin Oncol 2019; 37(15 Suppl): 11001. doi: 10.1200/ JCO.2019.37.15 suppl.11001

23. Nielsen OS, Cummings B, O'Sullivan B, Catton C, Bell RS, Fornasier VL. Preoperative and postoperative irradiation of soft tissue sarcomas: effect of radiation field size. Int J Radiat Oncol Biol Phys 1991; 21: 1595-9. doi: 10.1016/0360-3016(91)90337-4

24. Sindelar WF, Kinsella TJ. Normal tissue tolerance to intraoperative radiotherapy. Surg Oncol Clin N Am 2003; 12: 925-42. doi: 10.1016/s10553207(03)00087-5

25. Pawlik TM, Ahuja N, Herman JM. The role of radiation in retroperitoneal sarcomas: a surgical perspective. Curr Opin Oncol 2007; 19: 359-66. doi: $10.1097 / \mathrm{cco} .0 \mathrm{~b} 013 \mathrm{e} 328122 \mathrm{~d} 757$

26. Virkus WW, Mollabashy A, Reith JD, Zlotecki RA, Berrey BH, Scarborough MT. Preoperative radiotherapy in the treatment of soft tissue sarcomas. Clin Orthop Relat Res 2002; 397: 177-89. doi: 10.1097/00003086-20020400000022

27. Niewald M, Fleckenstein J, Licht N, Bleuzen C, Ruebe C. Intraoperative radiotherapy (IORT) combined with external beam radiotherapy (EBRT) for soft-tissue sarcomas - a retrospective evaluation of the Homburg experience in the years 1995-2007. Radiat Oncol 2009; 4: 32. doi: 10.1186/1748717X-4-32

28. Kim HJ, Koom WS, Cho J, Kim HS, Suh CO. Efficacy of postoperative radiotherapy using modern techniques in patients with retroperitoneal soft tissue sarcoma. Yonsei Med J 2018; 59: 1049-56. doi: 10.3349/ ymj.2018.59.9.1049

29. Cosper PF, Olsen J, DeWees T, Van Tine BA, Hawkins W, Michalski J, et al. Intensity modulated radiation therapy and surgery for management of retroperitoneal sarcomas: a single-institution experience. Radiat Oncol 2017 12: 198. doi: 10.1186/s13014-017-0920-y

30. El-Bared N, Wong P, Wang D. Soft tissue sarcoma and radiation therapy advances, impact on toxicity. Curr Treat Options Oncol 2015; 16: 19. doi: 10.1007/s11864-015-0335-7 